dependence are few and far between, with only four reports published in the last forty years. ${ }^{[1-4]}$ This is surprising, given the fact that mephentermine is $\mathrm{N}, \alpha$, dimethylamphetamine, bearing a close structural similarity to methamphetamine. Mephentermine is used as a vasopressor agent with a sympathomimetic action, primarily causing release of noradrenaline and increasing cardiac output. It is available in India as $10 \mathrm{mg}$ oral tablets and also as intramuscular or intravenous injection of $15 \mathrm{mg} / \mathrm{ml}$ or $30 \mathrm{mg} / \mathrm{ml}$. The injectable preparation is indicated for the short-term treatment of various hypotensive states, usually in the acute or emergency phase, e.g., shock or hypotension accompanying myocardial infarction or other severe medical illnesses, spinal anesthesia or surgical procedures. The standard parenteral dose range is $15-60 \mathrm{mg} / \mathrm{d}$ either as injection or intravenous infusion.

A 39-year-old married graduate bank employee, started drinking and smoking cigarettes since 1995. In December 2003, when his mother was admitted in the coronary care unit, a paramedical worker in the hospital casually commented on his 'cold limbs' and advised him to take intravenous (IV) mephentermine, as that person said he was using the same drug for a similar purpose. Following an IV dose administered by his unsolicited advisor-cum-peer, he perceived 'stimulation in nerves', increased energy and pleasurable sensations. After two months of

\section{MEPHENTERMINE DEPENDENCE WITHOUT PSYCHOSIS}

Sir,

Reports of mephentermine misuse or irregular use, he started taking $2 \mathrm{ml} \mathrm{Termin}^{\mathrm{R}}$ (15 $\mathrm{mg} / \mathrm{ml}$ preparation of mephentermine) IV twice daily regularly $(60 \mathrm{mg} / \mathrm{d})$. He gradually started craving the drug and reported a sense of compulsion to continue taking it. 
From the middle of 2004 onwards, he experienced withdrawal features in the form of decreased pulse rate and blood pressure, restlessness, cold extremities, sweating, anorexia, irritability, and insomnia. There was evidence of harm in the form of multiple injection-related skin infections and repeated withdrawal-related hypotensive episodes. Despite this, he found it difficult to stop taking the injection or reduce its dose. Presence of these withdrawal features, along with the continued perception of the stimulant effect of the drug, made him continue with this on a regular daily basis until December 2005. He would use capsule Proxyvon off-and-on since 2004, only as a 'substitute drug' when Termin was not available or affordable.

From this scenario, by late December 2005 he was initiated into the use of injection buprenorphine with pheniramine and diazepam, as he discontinued mephentermine, not by choice but due to unavailability and increased cost. He quickly became dependent on the combination, was brought to our de-addiction centre in October 2006, and eventually hospitalized for de-addiction.

Two earlier reports were of mephentermine misuse without evidence of dependence..$^{[1,2]}$ In both the reports, misuse of mephentermine inhaler induced short-lasting acute paranoidhallucinatory psychosis, similar to amphetamine psychosis. Later, one case of mephentermine dependence associated with a chronic psychotic illness was reported. ${ }^{[3]}$ In the fourth case report, mephentermine use was reported only in combination with buprenorphine and promethazine, apparently to counteract the hypotension caused by the latter. ${ }^{[4]}$ Thus, although its misuse has been reported in the context of psychotic illness, a true mephentermine dependence syndrome without associated psychosis has not been reported.

Our patient clearly demonstrated ICD-10 substance dependence syndrome by meeting four out of six criteria for nearly two years: strong desire or sense of compulsion to use the substance, impaired control, withdrawal, and persistence despite harm. ${ }^{[5]}$

Thus, this case report shows that, although rarely reported, mephentermine use can cause dependence especially in an individual with multiple substance use, even without precipitating or occurring in the context of an amphetamine-like psychotic illness. Given its potential of causing harm due to hypertension, the abuse and dependence liability of mephentermine needs to be highlighted.

DEBASISH BASU, NARESH NEBHINANI Drug De-addiction and Treatment Centre, Department of Psychiatry, Postgraduate Institute of Medical Education and Research (PGIMER), Chandigarh, India

Correspondence: Dr. D. Basu, Department of Psychiatry, PGIMER, Chandigarh-160 012, India. E-mail: db_sm2002@yahoo.com

\section{REFERENCES}

1. Greenberg JR, Lustig N. Misuse of dristan inhaler. New York J Med 1966;66:613-7.

2. Angrist BM, Schweitzer JW, Gershon S, Freidhoff AJ. Mephentermine psychosis: Misuse of Wyamine inhaler. Am J Psychiatry 1970;126: 1315-7.

3. Joshi UG, Bhat SM. Mephentermine dependence with psychosis: A case report. Br J Psychiatry 1988;152:129-31.

4. Mendhekar DN, Sharma H, Dali JS. Case report 
of substance dependence with buprenorphine and mephentermine. Indian J Psychiatry 1999;41: 160-2.

5. World Health Organisation. The international classification of diseases, 10th ed. (ICD-10). Geneva: WHO; 1992.

DOI: $10.4103 / 0019-5359.49290$ 